\title{
Enantiomeric Separation of 2-(Phenoxy)propionate Derivatives by Chiral High-Performance Liquid Chromatography
}

\author{
SHU-LING LIN, AIH-JING CHIOU, SHIH-HSIUNG WU, AND KUNG-TSUNG WANG \\ Institute of Biological Chemistry, Academia Sinica and Graduate Institute of Biochemical Sciences, National \\ Taiwan University, Taipei, Taiwan, Republic of China
}

\begin{abstract}
Phenoxy)propionate derivatives were separated on three chiral columns, $\mathrm{OD}, \mathrm{OK}$, and chiral-2 columns. The chlorine substitution in the phenyl ring and the alcohol moiety of the ester groups of the derivatives had great influence for separation on the OD and OK columns, but little effect on the chiral-2 column.
\end{abstract}

KEY WORDS: chiral HPLC, 2-(phenoxy)propionate derivatives, Chiralcel OD column, Chiralcel OK column, chiral-2 column

\section{INTRODUCTION}

The measurement of optical purity of chiral compounds is one of the main fields in analytical chemistry. ${ }^{1}$ Particularly in the pharmaceutical and agricultural industry, the effect of racemic compounds usually resides primarily in one enantiomer, while the other enantiomer may produce adverse side effects. ${ }^{2,3}$ Several methods have been used to measure the optical purity of chiral compounds. ${ }^{1}$ Of all the methods, chiral chromatography is the most convenient and direct for quantitative and qualitative measurement. In the past years, more and more chiral columns have been developed and their mechanism of enantioseparation has been studied theoretically and experimentally. ${ }^{4-6}$

2-(Phenoxy)propionate derivatives are very important herbicides. Only the (R)-isomers are biologically active. The enantiomeric separations of the compounds have been carried out by lipase-catalyzed resolution 7,8 and their optical purities were easily detected by chiral high-performance liquid chromatography (HPLC). ${ }^{9}$ In this article, the Chiralcel columns such as OD, $\mathrm{OK}$, and chiral-2 are applied to separate the racemic derivatives and their separation mechanism is discussed.

\section{MATERIALS AND METHODS}

All solvents were HPLC grade and obtained from Alps Chem. Co. (Taiwan). 2-(Phenoxy)propionic acid, 2-(4-chlorophenoxy)propionic acid, 2-(3-chlorophenoxy)propionic acid, 2-(2-chlorophenoxy) propionic acid, and 2-(2,4-dichlorophenoxy)propionic acid were purchased from Aldrich Chemical Company and their esters derivatives were prepared by conventional chemical methods. The Chiralcel OD and OK columns (25 $\mathrm{cm} \times 4.6 \mathrm{~mm}$ i.d.) were products of Daicel Chemical Industries, Ltd. (Japan). The chiral-2 column was obtained from Macherey Nagel (Düren, Germany). An HPLC system of Waters Associates (Milford, MA) was used for the analytical separations, which consisted of one M6000A solvent delivery unit and a U6K Universal liquid chromatograph injector, coupled to a M450 variable-wavelength UV spectrophotometer and an SIC chromatocorder 12 integrator (System Instruments Co., Ltd., Japan).

Compounds 1-25 (shown in Scheme 1) were analyzed on a Chiralcel OD column at ambient temperature isocratically with $n$-hexane/isopropanol/formic acid (90:10:1, by volume) at a flow rate of $0.5 \mathrm{ml} / \mathrm{min}$ and detected at UV $254 \mathrm{~nm}$. The Chiralcel OK column and chiral-2 column were also performed in the same conditions as the OD column, except the elution with $n$-hexane/isopropanol ( $5: 1$, by volume) and $n$-heptane/isopropanol/trifluoroacetic acid (100:0.05:0.05, by volume), respectively.

\section{RESULTS AND DISCUSSION}

The separation results of the derivative compounds (Scheme 1) on Chiralcel OD column are given in Table 1. The results showed that the chlorine substitute in the phenyl ring of the compounds, regardless of ortho, meta, and para position, might decrease separation factors in the OD column. Furthermore, the chlorine substitution in a different position of the phenyl ring of the compounds caused a different extent of decreasing separation factors in the OD column. The order of separation factors of the acidic compounds was $\mathbf{5}$ (no chlorine) $>10$ (chlorine in the ortho position) $>15$ (chlorine in the meta position) $>20$ (chlorine in the para position) $=25$ (chlorine in the ortho and para positions). These indicated that the more compact and smaller the compounds was, the better the separation in the OD column. The order of separation factor of $1-5$ was $1>5>2>4>3$. This indicated that the alcohol moiety of the esters of the compounds also has great influence on separation in the OD column. In general, the bulky alcohol moiety such as $n$-butyl, cyclohexyl, and cyclopentyl in the ester was disadvantageous for separation in the OD col-

Received for publication April 25, 1991; accepted September 27, 1991. Address reprint requests to Shih-Hsiung Wu, Graduate Institute of Biochemical Sciences, National Taiwan University, P.O. Box 23-106, Taipei, Taiwan, Republic of China. 


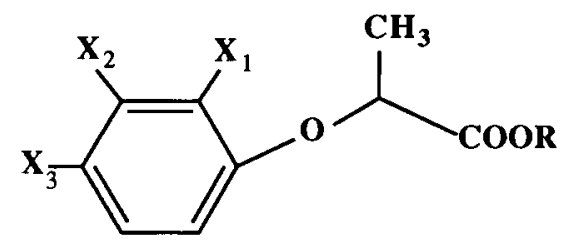

1: $\mathrm{X}_{1}=\mathrm{X}_{2}=\mathrm{X}_{3}=\mathrm{H} ; \mathrm{R}=-\mathrm{CH}_{3}$

2: $\mathrm{X}_{1}=\mathrm{X}_{2}=\mathrm{X}_{3}=\mathrm{H} ; \mathrm{R}=-\left(\mathrm{CH}_{2}\right)_{3} \mathrm{CH}_{3}$

3: $X_{1}=X_{2}=X_{3}=H ; R=-$ cyclopentyl

4: $X_{1}=X_{2}=X_{3}=H ; R=-$ cyclohexyl

5: $\mathrm{X}_{1}=\mathrm{X}_{2}=\mathrm{X}_{3}=\mathrm{H} ; \mathrm{R}=-\mathrm{H}$

6: $\mathrm{X}_{1}=\mathrm{Cl} ; \mathrm{X}_{2}=\mathrm{X}_{3}=\mathrm{H} ; \mathrm{R}=-\mathrm{CH}_{3}$

7: $\mathrm{X}_{1}=\mathrm{Cl} ; \mathrm{X}_{2}=\mathrm{X}_{3}=\mathrm{H} ; \mathrm{R}=-\left(\mathrm{CH}_{2}\right)_{3} \mathrm{CH}_{3}$

8: $\mathrm{X}_{1}=\mathrm{Cl} ; \mathrm{X}_{2}=\mathrm{X}_{3}=\mathrm{H} ; \mathrm{R}=$-cyclopentyl

9: $\mathrm{X}_{1}=\mathrm{Cl} ; \mathrm{X}_{2}=\mathrm{X}_{3}=\mathrm{H} ; \mathrm{R}=$-cyclohexyl

10: $\mathrm{X}_{1}=\mathrm{Cl} ; \mathrm{X}_{2}=\mathrm{X}_{3}=\mathrm{H} ; \mathrm{R}=-\mathrm{H}$

11: $\mathrm{X}_{2}=\mathrm{Cl} ; \mathrm{X}_{1}=\mathrm{X}_{3}=\mathrm{H} ; \mathrm{R}=-\mathrm{CH}_{3}$

12: $\mathrm{X}_{2}=\mathrm{Cl} ; \mathrm{X}_{1}=\mathrm{X}_{3}=\mathrm{H} ; \mathrm{R}=-\left(\mathrm{CH}_{2}\right)_{3} \mathrm{CH}_{3}$

13: $X_{2}=\mathrm{Cl} ; X_{1}=X_{3}=H ; R=-$ cyclopentyl

14: $\mathrm{X}_{2}=\mathrm{Cl} ; \mathrm{X}_{1}=\mathrm{X}_{3}=\mathrm{H} ; \mathrm{R}=$-cyclohexyl

15: $X_{2}=\mathrm{Cl} ; X_{1}=X_{3}=H ; R=-H$

16: $\mathrm{X}_{3}=\mathrm{Cl} ; \mathrm{X}_{1}=\mathrm{X}_{2}=\mathrm{H} ; \mathrm{R}=-\mathrm{CH}_{3}$

17: $\mathrm{X}_{3}=\mathrm{Cl} ; \mathrm{X}_{1}=\mathrm{X}_{2}=\mathrm{H} ; \mathrm{R}=-\left(\mathrm{CH}_{2}\right)_{3} \mathrm{CH}_{3}$

18: $X_{3}=C l ; X_{1}=X_{2}=H ; R=-c y c l o p e n t y l$

19: $X_{3}=\mathrm{Cl} ; X_{1}=X_{2}=H ; R=-$ cyclohexyl

20: $X_{3}=\mathrm{Cl} ; \mathrm{X}_{1}=\mathrm{X}_{2}=\mathrm{H} ; \mathrm{R}=-\mathrm{H}$

21: $\mathrm{X}_{2}=\mathrm{H} ; \mathrm{X}_{1}=\mathrm{X}_{3}=\mathrm{Cl} ; \mathrm{R}=-\mathrm{CH}_{3}$

22: $\mathrm{X}_{2}=\mathrm{H} ; \mathrm{X}_{1}=\mathrm{X}_{3}=\mathrm{Cl} ; \mathrm{R}=-\left(\mathrm{CH}_{2}\right)_{3} \mathrm{CH}_{3}$

23: $\mathrm{X}_{2}=\mathrm{H} ; \mathrm{X}_{1}=\mathrm{X}_{3}=\mathrm{Cl} ; \mathrm{R}=$-cyclopentyl

24: $X_{2}=H ; X_{1}=X_{3}=C l ; R=-$ cyclohexyl

25: $X_{2}=H ; X_{1}=X_{3}=C l ; R=-H$

Scheme 1.

umn, and the methyl ester derivatives $(\mathbf{1}, \mathbf{6}$, and 11) had slightly higher separation factors than acidic compounds $(\mathbf{5}$, 10 , and 15).

From the results shown in Table 2, the chlorine substitution in the phenyl ring of the compounds also had great influence on separation in the OK column. The order of separation factors for the methyl ester compounds is $16>1>11>6$ $=21$. This evidence showed that the separation of the compounds on the $\mathrm{OK}$ column largely depends on the conformational flexibility of the compounds. The chlorine substitution in the ortho or meta positions (6-15 and 21-25) completely or partially hinders the free rotation of the chemical bond between the phenoxyl group and 2-propionate of the compounds, and also loses the separation property on the OK column. The substitution in the para position (16-20) had no effect on molecular flexibility and might increase the aromatic $\pi-\pi$ bonding interaction; the separation factor was therefore higher than when there was no substitution (1-5). This result coincided with those of the previous reports-conformationally rigid solutes are not better resolved than flexible ones in the cellulose triacetyl chiral columns. ${ }^{10}$ The alcohol moiety of the esters of the compounds only had a small effect on separation factors on the OK column. However, the bulky alcohol moiety in ester groups could broaden the base of peaks in HPLC and
TABLE 1. Optical resolution of (R)- and (S)-2-(phenoxy)propionate derivatives by Chiralcel OD column

\begin{tabular}{|c|c|c|c|c|}
\hline \multirow[b]{2}{*}{ Compounds } & \multirow[b]{2}{*}{$\alpha$} & \multicolumn{2}{|c|}{$k^{\prime}$} & \multirow[b]{2}{*}{$R_{\mathrm{s}}$} \\
\hline & & $\mathrm{R}$ & $S$ & \\
\hline 1 & 2.48 & 1.24 & 0.50 & 2.35 \\
\hline 2 & 1.69 & 0.56 & 0.33 & 1.00 \\
\hline 3 & 1.00 & 0.33 & 0.33 & - \\
\hline 4 & 1.23 & 0.28 & 0.23 & 0.23 \\
\hline 5 & 2.07 & 1.76 & 0.85 & 2.60 \\
\hline 6 & 1.51 & 0.62 & 0.41 & 1.08 \\
\hline 7 & 1.32 & 0.30 & 0.23 & 0.44 \\
\hline 8 & 1.00 & 0.25 & 0.25 & - \\
\hline 9 & 1.00 & 0.21 & 0.21 & - \\
\hline 10 & 1.30 & 0.92 & 0.71 & 1.08 \\
\hline 11 & 1.22 & 0.40 & 0.33 & 0.42 \\
\hline 12 & 1.00 & 0.17 & 0.17 & - \\
\hline 13 & 1.00 & 0.22 & 0.22 & - \\
\hline 14 & 1.00 & 0.19 & 0.19 & - \\
\hline 15 & 1.14 & 0.63 & 0.55 & 0.67 \\
\hline 16 & 1.00 & 0.34 & 0.34 & $\ldots$ \\
\hline 17 & 1.00 & 0.18 & 0.18 & - \\
\hline 18 & 1.00 & 0.19 & 0.19 & - \\
\hline 19 & 1.00 & 0.15 & 0.15 & - \\
\hline 20 & 1.00 & 0.65 & 0.65 & - \\
\hline 21 & 1.00 & 0.35 & 0.35 & - \\
\hline 22 & 1.00 & 0.18 & 0.18 & $\ldots$ \\
\hline 23 & 1.00 & 0.20 & 0.20 & - \\
\hline 24 & 1.00 & 0.14 & 0.14 & - \\
\hline 25 & 1.00 & 0.59 & 0.59 & - \\
\hline
\end{tabular}

reduce the resolution factors. From the results shown in Tables 1 and 2 , the values of separation $(\alpha)$ and resolution factors $\left(R_{\mathrm{s}}\right)$ are proportional to those of capacity factors $\left(k^{\prime}\right)$, that is, the longer retention times are in the columns, the better resolutions are obtained. Therefore, the discussion between structure and $\alpha$ (or $R_{\mathrm{s}}$ ) can also be an explanation between structure and theoretical plates.

Although the stationary phases of both OK and OD columns are made of cellulose, the derivatives of cellulose on hydroxyl groups are quite different. The derivative of cellulose on the OK column is cinnamyl ester and on the OD column is phenylcarbamyl ester. From the results, the mechanism of separation of 1-25 on OD and OK columns seems to be quite different. It is believed that the fundamental mechanism of separation of chiral compounds on chiral columns which have polysaccharide derivatives as the stationary phase is mainly the inclusion effect. ${ }^{4}$ Beside the inclusion effect, secondary forces such as hydrogen bonding, hydrophobic interaction, and steric effect are involved. However, it is still difficult to explain why the flexible compounds are better resolved on the OK column and the rigid ones are better resolved on the OD column. These results illustrate the complexity of the chiral recognition mechanism in these types of chiral columns.

Chiral-2 is a Pirkle-type chiral column. Its stationary phase is silica gel bonded with $N$-(3,5-dinitrobenzoyl) derivatives as a chiral selector. The separation mechanism of the chiral-2 col- 
TABLE 2. Optical resolution of (R)- and (S)-2-(phenoxy)propionate derivatives by Chiralcel OK column

\begin{tabular}{lllll}
\hline & & \multicolumn{3}{c}{$k^{\prime}$} \\
\cline { 3 - 5 } Compounds & & $\mathrm{R}$ & $\mathrm{S}$ & $R_{\mathrm{s}}$ \\
\hline $\mathbf{1}$ & $\alpha$ & 1.64 & 2.27 & 2.27 \\
$\mathbf{2}$ & 1.38 & 0.64 & 0.88 & 0.90 \\
$\mathbf{3}$ & 1.37 & 0.71 & 0.96 & 1.08 \\
$\mathbf{4}$ & 1.35 & 0.51 & 0.60 & 0.56 \\
$\mathbf{5}$ & 1.17 & 0.65 & 0.88 & 0.83 \\
$\mathbf{6}$ & 1.33 & 1.67 & 1.67 & - \\
$\mathbf{7}$ & 1.00 & 0.66 & 0.66 & - \\
$\mathbf{8}$ & 1.00 & 0.73 & 0.73 & - \\
$\mathbf{9}$ & 1.00 & 0.60 & 0.60 & - \\
$\mathbf{1 0}$ & 1.00 & 0.75 & 0.75 & - \\
$\mathbf{1 1}$ & 1.00 & 1.34 & 1.51 & 0.80 \\
$\mathbf{1 2}$ & 1.13 & 0.58 & 0.58 & - \\
$\mathbf{1 3}$ & 1.00 & 0.63 & 0.63 & - \\
$\mathbf{1 4}$ & 1.00 & 0.49 & 0.49 & - \\
$\mathbf{1 5}$ & 1.00 & 0.51 & 0.51 & - \\
$\mathbf{1 6}$ & 1.00 & 1.55 & 2.59 & 3.79 \\
$\mathbf{1 7}$ & 1.67 & 0.64 & 1.06 & 1.56 \\
$\mathbf{1 8}$ & 1.65 & 0.73 & 1.12 & 1.33 \\
$\mathbf{1 9}$ & 1.53 & 0.55 & 0.73 & 0.78 \\
$\mathbf{2 0}$ & 1.32 & 0.65 & 1.12 & 2.29 \\
$\mathbf{2 1}$ & 1.72 & 1.58 & 1.58 & - \\
$\mathbf{2 2}$ & 1.00 & 0.64 & 0.64 & - \\
$\mathbf{2 3}$ & 1.00 & 0.71 & 0.71 & - \\
$\mathbf{2 4}$ & 1.00 & 0.50 & 0.50 & - \\
$\mathbf{2 5}$ & 1.00 & 0.68 & 0.68 & - \\
\hline & 1.00 & & &
\end{tabular}

umn is believed to obey Daligliesh's three-point interaction theory, and charge-transfer interactions, hydrogen-bonding, dipole stacking interactions, and steric effects are involved. ${ }^{11}$ The chlorine substitution in the phenyl ring and alcohol moiety in the ester of the compounds make the main skeleton of the compounds change little. This is the reason the separation factors of compounds 1-25 on the chiral-2 column were almost constant (Table 3). The acidic compounds $(5,10,15,20$, and 25) could not be eluted on the chiral-2 column due to their high polarity. Because methyl 2-phenylpropionate could not be separated on the chiral-2 column, the oxygen atom which connects the phenyl group and 2-propionate of the compounds played an important role in the separation of the compounds on the chiral-2 column.

The enantiomeric ratios $(E)$ of the methyl ester compounds $(1,6,11,16$, and 21) by the resolution of the lipase from Candida cylindracea have been determined, and the order of their $E$ values were consistent with those of their separation factors and resolution factors on the OK column (Table 4). These comparisons implied that the chiral recognition toward the racemic compounds by the cavity of the OK column may have a similar mechanism to that of the active site of the lipase. Therefore, it is possible to have an artificial asymmetric environment for chiral recognition which is similar to those by natural biocatalysts. This may be a way to elucidate the complexity of living chiral systems by studying simpler and biomimetic organic systems.
TABLE 3. Optical resolution of (R)- and (S)-2-(phenoxy)propionate derivatives by Chiral-2 column

\begin{tabular}{|c|c|c|c|c|}
\hline \multirow[b]{2}{*}{ Compounds } & \multirow[b]{2}{*}{$\alpha$} & \multicolumn{2}{|c|}{$k^{\prime}$} & \multirow[b]{2}{*}{$R_{\mathrm{s}}$} \\
\hline & & $\mathrm{R}$ & S & \\
\hline 1 & 1.22 & 4.44 & 5.40 & 2.36 \\
\hline 2 & 1.22 & 3.62 & 4.41 & 1.93 \\
\hline 3 & 1.23 & 3.83 & 4.71 & 2.10 \\
\hline 4 & 1.24 & 3.64 & 4.52 & 1.84 \\
\hline 5 & - & - & - & - \\
\hline 6 & 1.22 & 4.80 & 5.85 & 1.79 \\
\hline 7 & 1.20 & 4.03 & 4.82 & 1.54 \\
\hline 8 & 1.19 & 4.34 & 5.19 & 1.43 \\
\hline 9 & 1.22 & 4.21 & 5.13 & 2.08 \\
\hline 10 & - & - & - & - \\
\hline 11 & 1.19 & 3.05 & 3.63 & 1.07 \\
\hline 12 & 1.20 & 2.55 & 3.06 & 1.86 \\
\hline 13 & 1.17 & 2.75 & 3.23 & 1.63 \\
\hline 14 & 1.19 & 2.59 & 3.09 & 1.62 \\
\hline 15 & - & - & - & - \\
\hline 16 & 1.28 & 2.79 & 3.58 & 1.66 \\
\hline 17 & 1.30 & 2.25 & 2.93 & 1.58 \\
\hline 18 & 1.31 & 2.54 & 3.32 & 1.49 \\
\hline 19 & 1.34 & 2.38 & 3.20 & 1.42 \\
\hline 20 & - & - & - & - \\
\hline 21 & 1.21 & 2.73 & 3.23 & 1.17 \\
\hline 22 & 1.21 & 2.08 & 2.52 & 1.67 \\
\hline 23 & 1.22 & 2.18 & 2.67 & 1.73 \\
\hline 24 & 1.25 & 2.01 & 2.51 & 1.63 \\
\hline 25 & - & - & - & - \\
\hline
\end{tabular}

TABLE 4. Comparison of separation factors $(\alpha)$ and resolution factors $\left(R_{\mathrm{s}}\right)$ of compounds $1,6,11,16$, and 21 on the Chiralcel OK column with the enantiomeric ratios (E) resolved by the lipase from Candida cylindracea

\begin{tabular}{lccr}
\hline & \multicolumn{2}{c}{ OK column } & \\
\cline { 2 - 4 } Compounds & $\alpha$ & $R_{\mathrm{s}}$ & $E^{b}$ \\
\hline $\mathbf{1}$ & 1.38 & 2.27 & 11 \\
$\mathbf{6}$ & 1.00 & - & 2 \\
$\mathbf{1 1}$ & 1.13 & 0.80 & 4 \\
$\mathbf{1 6}$ & 1.67 & 3.08 & 17 \\
$\mathbf{2 1}$ & 1.00 & - & 1 \\
\hline
\end{tabular}

The $E$ values were cited from the results of Guo and $\operatorname{Sin}^{7}$ and were also confirmed by our group.

\section{LITERATURE CITED}

1. Morrison, J. D., ed. Asymmetric Synthesis, Vol. 1. London: Academic Press, 1983.

2. Simonyi. M. On chiral drug action. Med. Res. Rev, 4:359-413, 1984.

3. Borman, S. Chirality emerges as key issue in pharmaceutical research. Chem. Engineer. News 68(28):9-14, 1990.

4. Allenmark, S. G. Chromatographic Enantioseparation: Methods and Applications. London: Ellis Horwood, 1988.

5. Armstrong, D. W. Optical isomer separation by liquid chromatography. Anal. Chem. 59:84A-91A, 1987. 
6. Schurig, V., Nowotny, H-P. Gas chromatographic separation of enantiomers on cyclodextrin derivatives. Angew. Chem. Int. Ed. Engl. 29:939-957, 1990.

7. Guo, Z. W., Sih, C. J. Enantioselective inhibition: A strategy for improving the enantioselectivity of biocatalytic systems. J. Am. Chem. Soc. 111:68366841, 1989.

8. Cambou, B., Klibanov, A. M. Comparison of different strategies for the lipase-catalyzed preparative resolution of racemic acids alcohols: Asymmetric hydrolysis, esterification, and transesterification. Biotechnol. Bioeng. 26:1449-1454, 1984.
9. Wu, S. H., Lai, S. Y., Lin, S. L., Chu, F. Y., Wang, K. T. Direct measurement of enantiomeric ratios of enzymatic resolution by chiral high-performance liquid chromatography. Chirality 3:67-70, 1991.

10. Shibata, T., Okamota, I., Ishii, K. Chromatographic optical resolution On polysaccharides and their derivatives. J. Liquid Chromatogr. 9:313-340, 1986.

11. Pirkle, W. H., Pochapsky, T. C. Considerations of chiral recognition relevant to the liquid chromatographic separation of enantiomers. Chem. Rev. 89:347-362, 1989. 